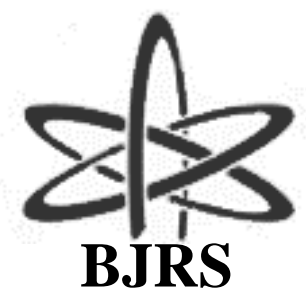

BRAZILIAN JOURNAL

$\mathrm{OF}$

RADIATION SCIENCES

08-03A (2020) 01-17

\title{
Nuclear qualification of electrical equipment: challenges for the Brazilian industry
}

\author{
Bongiolo $^{\mathrm{a}}$ G.G., Silva ${ }^{\mathrm{b}}$ C.R., Moreira ${ }^{\mathrm{b}}$ J.M.L. \\ ${ }^{a}$ Universidade de São Paulo \\ Av. Professor Luciano Gualberto 380, 05508-010 São Paulo, SP, Brazil \\ ${ }^{b}$ Programa de Pós-graduação em Energia, Universidade Federal do ABC \\ Av. dos Estados 5001, 09210-580 Santo André, SP, Brazil \\ joao.moreira@ufabc.edu.br
}

\begin{abstract}
The nuclear industry requires specific safety qualification of electrical equipment in order to assure that they perform their function without experiencing common-cause failures. Electrical equipment used in the nuclear industry have been qualified according to IEEE 323 and IEC 60780 standards and their derivatives until 2016. Currently these two organizations consolidated their requirements and unified them in a common document, the IEC/IEEE 60780-323 standard. It defines the different methods of qualification, a qualification program plan and the documentation to be delivered demonstrating successful qualification of electrical equipment to be used in nuclear installations. Based on this standard, we present an approach focusing on the qualification by typetesting. The article details the necessary tests to be performed for this method, the equipment necessary to be used in the type-testing method and the documentation expected to be delivered by the supplier. To implement this qualification approach and obtain such capacity, it is necessary to perform large expenditures in equipment and in the improvement of the workforce. On the other hand, this capacity gives the companies knowledge, experience and opens new market opportunities in other areas, such as the naval and oil industries. With such expertise, Brazilian companies may become active suppliers in the world industry of electrical equipment.
\end{abstract}

Keywords: qualifying, electric equipment, nuclear power. 


\section{INTRODUCTION}

The nuclear industry requires specific safety qualification of all the equipment in order to ensure that the equipment and systems will operate and meet requirements including most hazardous service conditions. The qualification is considered one of the defence-in-depth methods for protection against the release of radioactive materials. This kind of qualification was discussed during the Convention on Nuclear Safety promoted by the International Atomic Energy Agency (IEAE) in Vienna in 1994. The Convention presented objectives to warrant safety of nuclear power operation which should provide several reliable levels and methods of protection against the release of radioactive materials, such as physical separation by protective barriers or distance, redundancy linked with diversity and qualification of the technologies important to safety incorporated in the NPPs [[1],[2]].

Qualification of equipment important to safety in NPPs ensures its capability to perform defined safety functions on demand throughout the entire life of the plant, even during or after postulated service conditions, considering the effects of the equipment ageing. These postulated service conditions include harsh accident environment (e.g. loss of coolant (LOCA), high-energy line break (HELB) and seismic or other vibration conditions) [[2]].

Such qualification is necessary because the conditions under which equipment is required to perform safety function differ from those to which it is exposed during normal operation. Among the environmental conditions the design should consider a wide range of accidents, including extremes of temperature, pressure, radiation, vibration, humidity and jet impingement, interdependencies and severe accidents. Ageing is taken into account in the design by the appropriate specification of environmental conditions, process conditions, duty cycles, maintenance schedules, service lifetime, type-testing schedules, replacement parts and replacement intervals [[3]].

The IAEA Safety Guide on General Design Safety Principles of Nuclear Power Plants presents guidelines to equipment qualification (EQ) in general, stating the possible methods of qualification. These methods are the test of a prototype equipment, the test of the actual equipment to be supplied, 
analysis of operating experience of equipment in similar applications and analysis based on extrapolation of test data or operating experience under pertinent conditions [[4]].

This paper deals specifically with the qualification of electrical equipment, whose requirements are foreseen by various international and national standards, codes and guides. For example, the standard produced by the International Electrotechnical Commission (IEC) along with the American Institute of Electrical and Electronics Engineering (IEEE): IEC/IEEE 60780-323 [[5]]; the French National Codes like RCC-E [[6]]; the Chinese National Standards as GB/T 36044-2018 [[7]], among others.

We analyze the standard IEC-IEEE 60780/323, aiming at presenting the qualification methods., We center the analysis on the type-testing and include comments from international qualification experience. We present the tests that shall be performed, the type of equipment necessary to perform them, the expected documentation to be provided, the necessities to qualify the production line and the workforce and the main impacts of being capable to perform such qualification.

\section{METHODS FOR QUALIFICATION OF ELECTRICAL EQUIPMENT}

Electrical equipment used in the nuclear industry have been mainly qualified according to IEEE 323 and IEC 60780 standards and their derivatives until 2016.

The subcommittee 45A from the IEC, which deals with instrumentation, control and electrical systems of nuclear facilities, prepared the standard IEC 60780. This subcommittee is part of the committee 45 (Nuclear Instrumentation). The standard IEC 60680 derives from the first level of IEC SC 45A document, the standard IEC 61513, which provides general requirements for Instrumentation and Control (I\&C) systems and equipment required to perform important safety functions in NPPs [[8]]. The standard IEC 60780 is a second level IEC SC 45A document, which is focused on the environmental qualification of electrical equipment important to safety. At the third level, the standards are related to specific equipment, technical methods or specific activities. The IEC SC 45A standards are based in the basic safety aspects provided in the IAEA code on the safety of NPPs and in the IAEA safety series. 
The standard IEEE 323 was created by the Subcommittee 2 of IEEE, which treats the qualification of safety-related systems and equipment in nuclear power generating stations. These equipment are called Class $1 \mathrm{E}$ and derives from the IEEE 603, which establishes the minimum functional and design criteria for the power, instrumentation, and control portions of nuclear power generating station safety systems [[9]]. The standard IEEE 323 is the reference for other IEEE standards that deal with the qualification of specific equipment, e.g. IEEE 650 - Qualification on Class 1E Battery Charges and Inverters, IEEE 334 - Qualification of Continuous Duty Class 1E Motors, among others.

Currently these two organizations consolidated their requirements and unified them in a common document, the IEC/IEEE 60780-323 standard. This measure was adopted because there was little coordination between the two sets of standards. This caused problems for the developers trying to address both set of standards to reach broader markets [[10]].

\subsection{IEC/IEEE 60780-323}

The standard IEC/IEEE 60780-323 has the objective of presenting the basic requirements for qualifying electrical equipment important to safety that are used in NPPs. It specifies principles, methods and procedures to be used in the qualification, maintenance, extension of qualification, or even the update of the qualification when the equipment is modified. When the requirements of the standard are met, the documentation produced will demonstrate the ability of the equipment to perform safety functions under service conditions, including design basis events (DBE) and reduce the risk of environmentally induced common-cause equipment failure [[5]].

The essential elements required to demonstrate the equipment qualification include:

- Equipment specification including the safety function(s);

- Acceptance criteria;

- Definition of the service conditions, including DBEs;

- Definition and implementation of the qualification programme plan:

○ Qualification of new equipment:

- Type-testing;

- Operating experience; 
- Analysis;

- Combined methods;

○ Condition-based qualification;

- Documentation demonstrating successful qualification.

The following sub-sections briefly describe each element, focusing on the description of the type-testing qualification.

\subsection{Equipment specification}

The designers of the NPP and respective electrical equipment shall provide essential information about the equipment to be qualified. This specification shall include:

- A technical description of the equipment, including applicable performances, qualification standards, internal design and the required performance of the device;

- The interfaces between the electrical and mechanical connections, motive power or control signal inputs/outputs, control, indicating and other auxiliary components;

- The qualified life objective;

- The safety function(s), including the required operating times;

- Normal and abnormal service conditions, including nominal and extreme values and their respective durations. Example of service conditions are ambient pressure and temperature, radiation environment, seismic and non-seismic vibration, relative humidity, electromagnetic conditions, among others; and

- The postulated DBE conditions, e.g. high-energy line break (HELB), loss-of-coolant accident (LOCA), main steam line break and/or seismic events. These conditions shall be specified when the equipment shall operate during or after the DBEs.

\subsection{Qualification programme plan - Implementation}

The qualification programme is defined elsewhere [5]. The methods of qualification allowed to be used according to the standard are type-testing, operating experience and analysis. 


\section{a) Type-testing}

The type test qualification method is the preferable one to be used. The test shall be conducted rather with a representative sample of equipment. To perform the test, the equipment shall be mounted and connected in a manner and position that simulates its expected installation, choosing the worst case position. In the case that the qualification is performed with different mounting and connections, analysis is required to demonstrate that the performance is not degraded.

During testing, both the environment and the equipment's safety function(s) shall be monitored, using calibrated equipment (methods of calibration shall be documented). Measurements shall be performed in the environmental conditions, electrical, fluid, mechanical characteristics, radiological features, and any auxiliary features.

The test sequence of the type test methods is shown in Fig. 1. The sequence shows that the sample shall be deteriorated until the worst state expected, prior to the application of the DBE and performance of the safety function.

Figure 1: Type-testing sequence.

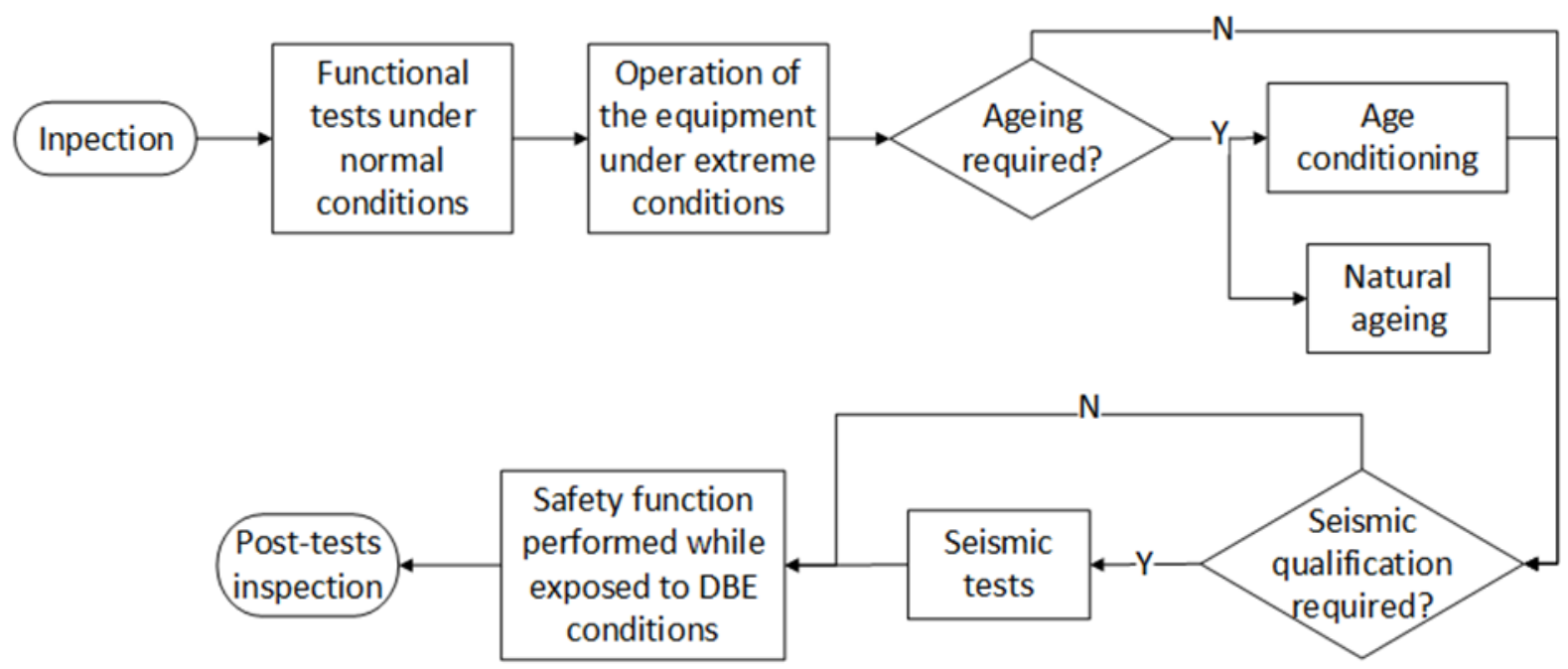

First, the inspection shall identify the test sample and ensure that it is exactly as specified and not damaged. Next, functional test shall be performed under normal conditions. Then, the sample shall be operated under the extreme conditions of all performances. For convenience, this operation 
may be performed on a separate test specimen or be proven by data from other tests on identical or similar equipment.

The equipment shall be reviewed to identify potentially significant ageing mechanisms, which are responsible to degrade the equipment while in storage and/or in the service environment that substantially renders the equipment vulnerable to failure its safety function under accident conditions. In this case, suitable age conditioning shall be included in the type test. After the ageing, measurements or functional tests shall be performed to ensure the performance of the sample at the end of its expected qualified life.

The equipment may be aged by natural ageing or age conditioning:

- The natural ageing method might be used in equipment that have been operated under conditions at least as severe as those specified, since documentation to prove it and operating/maintenance records are available. In this case, the need to identify significant ageing mechanisms is avoided;

- The age conditioning method is a process that replicates, in a short period (generally between one or two months), the degradation of equipment during the expected qualified life. This degradation involves applying simulated in-service stresses, which significantly age the equipment, such as thermal, radiation, moisture, wear and vibration. The estimation of the degradation should consider sequential, simultaneous and synergistic effects. In the case that only sequential tests are performed, the sample shall be submitted in a conservative sequence to maximize the ageing effects and margins shall be added to ensure that the qualified life condition is not overestimated. When the ageing tests are simultaneous, it shall be verified if the acceleration of the parameters does not alter the expected ageing effects. During the age conditioning, the equipment shall be energized and be periodically checked. If not continuously energized, it shall be justified that the thermal heating due to being energized was taken into account.

○ To accelerate the thermal effects, it is acceptable to use the Arrhenius methodology. The acceleration factor is determined by the ratio of the rate of degradation at the 
elevated temperature to the rate of degradation at normal operation ${ }^{1}$. To complex equipment, an uncertainty is observed in the application of the acceleration factor, as different chemical processes may happen at higher temperatures, thus a limit to the acceleration factor shall be applied. For example, according to Swedish experience the thermal acceleration factor shall be limited to 250 for most of materials [[11]]. In this case, an expected qualified life of 40 years, could be simulated in 2 months;

○ Dose rate acceleration is acceptable for radiation degradation effects. The equipment shall be subjected in short time to the total expected life-time dose. The acceleration factor is defined as the ratio between the dose-rate at testing and the dose-rate at normal operation. This factor shall be determined considering the effects of oxidation and gaseous diffusion, thus margins shall be adopted to ensure that the simulated qualified life is not overestimated. As observed in [[11]], for ionising radiation below $1 \mathrm{kGy}$ during the qualified life, the effects of radiation are neglible. The degradation also depends on the dose-rate and the definition of this rate to age the equipment is different for several countries (e.g. Japan uses $1 \mathrm{kGy} / \mathrm{h}$, France uses 3 to $10 \mathrm{~Gy} / \mathrm{h}[[11]])$. In the case that the equipment is too great to be fitted inside the test facility, the radiation sensitive components can be removed and aged, before reassembling them. This shall be subject to the purchaser approval;

- The mechanical ageing shall be considered in the simulation of the operational cycle of the equipment and of the non-seismic vibration during normal and abnormal conditions. While the electrical ageing shall be emulated in the simulation of the operational cycle of the equipment (e.g. number of trips during the whole life) and in the application of voltage variations, as impulse voltages. The components degraded due to wear ageing shall be identified and their interval replacement shall be documented;

\footnotetext{
${ }^{1}$ The rate of thermal degradation using the Arrhenius methodology is determined by the relationship: $r=A e^{-{ }^{E} / k T}$, where $r$ is the rate of degradation, $E$ is the activation energy $(\mathrm{eV}), k$ is the Bolzmann's constant $\left(0,86 \times 10^{-4} \mathrm{eV} / \mathrm{K}\right)$ and $T$ is the temperature (K) [[12]].
} 
- The main ageing were described in the topics above, however if any other condition that age the equipment as well is observed, it shall be included in the programme (e.g. humidity)

After that and if required, the test sample shall be subjected to simulated seismic vibration according to IEEE Std 344 or IEC 60980. Currently, an effort between both institutions is being performed to harmonize both standards.

Right after, the sample shall be subjected to accident conditions. During the simulation of the DBE and post it, the equipment shall be energized and monitored in order to demonstrate the ability of the equipment to perform its specified safety function. Normally, the equipment is subjected to an ionising radiation expected in the DBE, followed by a hot steam at high pressure (in this case, the DBE is the LOCA). For the simulation of the DBE conditions, margins shall be applied to the specified values of peak temperature $\left(+8^{\circ} \mathrm{C}\right)$, peak gauge pressure profile $(+10 \%)$, total radiation dose $(+10 \%)$, power supply voltage $(+-10 \%)$, frequency $(+-5 \%)$, equipment operating time after the start of the DBE (+-10\%) and seismic vibration at the mounting point $(+10 \%)$.

Finally after these tests, the equipment shall be visually inspected.

The condition-based qualification is an adjunct to the type-testing qualification. For this case, it is necessary to perform the age conditioning incrementally and compare condition indicators to the same indicators observed during service. The condition indicators shall be chosen in a manner that their variation in function of the ageing shall be known and they shall be related to the degradation of parameters important to the operation of the equipment. This method has the advantage of not depending on the calculation of acceleration factors and on knowing how the synergism of the combined ageing conditions affect the equipment [[11]].

b) Operating experience

Operating experience may be used when the same or similar equipment has functioned under service conditions at least as severe as the specification. Differences in the equipment, in the service conditions or the use of equipment performing non-safety functions shall be justified, ensuring that they do not reduce the equipment capability of performing the safety functions. This type of qualification can only be used, when documentation with auditable data is available. The documentation shall include test records, analyses of failures, description of periodic maintenance, inspections and the characteristics of arrangement of the equipment in the operating facility. 
c) Analysis

Analysis methods may be used to supplement the demonstration of qualification, for both type test and operating experience methods. Among the techniques of analysis are extrapolation and interpolation. The analysis consist in demonstrating that the equipment is able to operate in a different condition than the one that it was specified.

Another technique is the use of equipment similarity to demonstrate the equivalency between the equipment desired to be qualified and another already qualified. The similarity is analyzed through:

- The materials of construction;

- The design;

- The manufacturing process;

- The physical size (in case of variation, it shall be ensured that the basic configuration is the same and factors shall be applied to consider the thermal and seismic effects applied to equipment with different surface areas and different masses/centre of gravity);

- The service and operating conditions shall be equal or less restrictive than the equipment already qualified;

- The installation of the equipment shall be the same or any difference shall be justified;

- The ageing mechanisms of the qualified equipment shall encompass the specified one ; and

- The function important to safety shall be the same.

d) Modifications

In the case that the equipment or the qualification procedures are modified after the completion of the qualification program, it shall be analyzed if additional steps are required. Modifications in the design, material, arrangement, safety function acceptance criteria, DBE shall be analyzed and the justification shall be included in the qualification documentation. 


\subsection{Documentation}

After the tests of the equipment, the Supplier shall provide the documentation to provide evidence that the equipment is qualified for the application and meets the acceptance criteria established in the specification. The documentation shall include:

- Identification of the equipment;

- Identification of the functions important to safety;

- Identification of the installation of the equipment, including mounting, orientation, electrical and mechanical interfaces;

- Identification of the normal environmental conditions, the design basis events and the accidental conditions;

- Evaluation of the signification ageing mechanisms, of the methods to address them in the programme and the results of the age conditioning, if applicable;

- Identification of margin, if applicable;

- Identification of the qualified condition of the equipment;

- Presentation of the seismic result when applicable;

- Identification of the accident test results, including a description with graphics of the applied conditions;

- Identification of scheduled maintenance, periodic tests or components replacements to maintain qualification; and

- Summary and conclusions.

For the type testing method, the qualification method shall be identified and descripted; the test sample, the acceptance criteria and results shall be identified; the test sequence shall be explained; the justification of the representativeness of the test sample shall be justified; test anomalies shall be evaluated and the conformance with normal and abnormal environment shall be presented. 


\section{RESULTS AND DISCUSSION}

\subsection{Application in the Brazilin industry}

The Brazilian projects in the nuclear sector include a nuclear power plant, a submarine prototype, a nuclear submarine, and a reactor for production of radioisotopes. These projects are expected to be concluded in the next decade. They require companies sited in the country capable to manufacture and qualify electrical equipment with programmes as described in sect. 2 . There are companies with technical expertise to develop and manufacture such electrical and I\&C systems. For instance, WEG, located located in Jaraguá do Sul - SC, is capable to develop and manufacture electric motors, transformers, and generators, but they require to be qualified. To do that the companies, or outsourced Brazilian institutes or universitie, have to undertake investment in technical infrastructure and trained labor force to conduct the numerous tests described in sect. 2.

Considering the type-testing method of qualification, the tests require emulating the normal/extreme environmental conditions to age the equipment, emulating DBE conditions and to perform the seismic tests. To simulate the environmental conditions it is necessary climatic chambers to emulate reactor primary circuit and containment conditions of temperature, humidity and pressure. Additionally, it is necessary to emulate actual equipment vibration in vibration tables. It is possible to find commercial solutions to simulate all these conditions in a single chamber. For example, the company Weiss Technik sells this kind of product as presented in Fig. 2. For testing larger equipment one needs to construct special test chambers.

Figure 2: Vibration and environmental chamber - Weiss Technik Company [[15]]. 


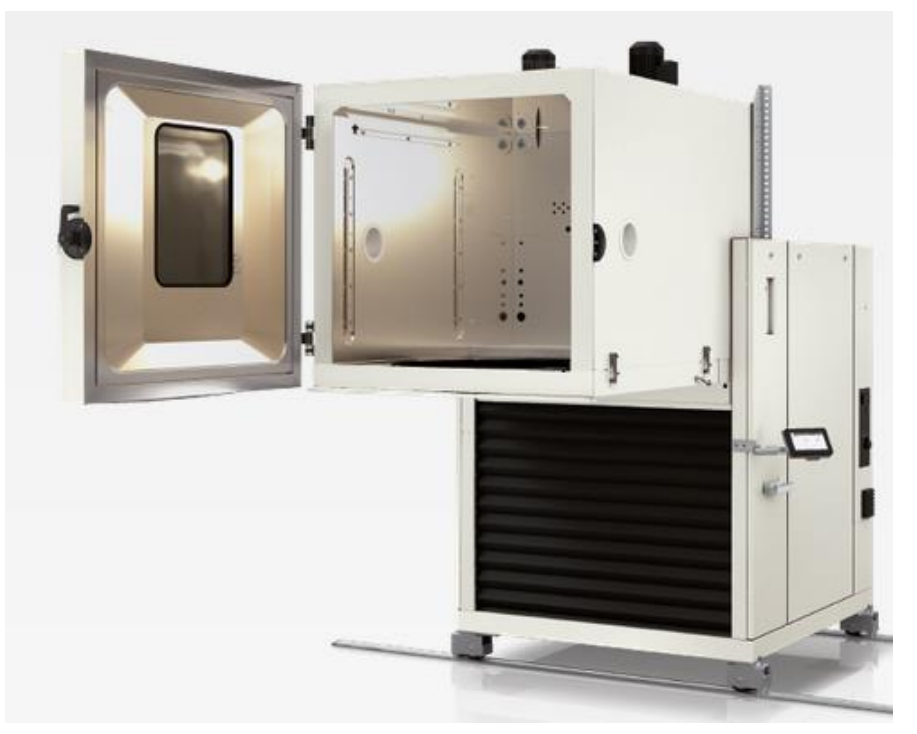

For ageing conditioning, it is necessary a temperature chamber equipped with several sensors insulated against heat radiation from surrounding surfaces. For self-heated equipment, it shall be considered that it dissipates the heat, so the estimation of the qualified life could be underestimate [[11]].

For radiation conditioning, it is necessary a gamma ray ionizer and an ionising chamber. Ideally, thermal and radiation conditioning shall be performed in the same chamber to consider the synergetic effect of simultaneous application of different parameters. The measurement of the ionising radiation shall be performed in in the vicinity of the components under test and not only in general areas [[11]].

After the ageing and if required, seismic vibrations may be performed in specific tri-axial seismic shake table. Earthquake tests are done with hydraulic excitation due to the low frequency. They are most often done with three axes simultaneously, but it is also common to see one or two axes of test. One example of test table used in the Applied Technical Services Laboratory in Atlanta is shown in Fig. 3.

Figure 3: Exciter 3D Vibration Test System - Link Company [Erro! Fonte de referência não encontrada.]. 


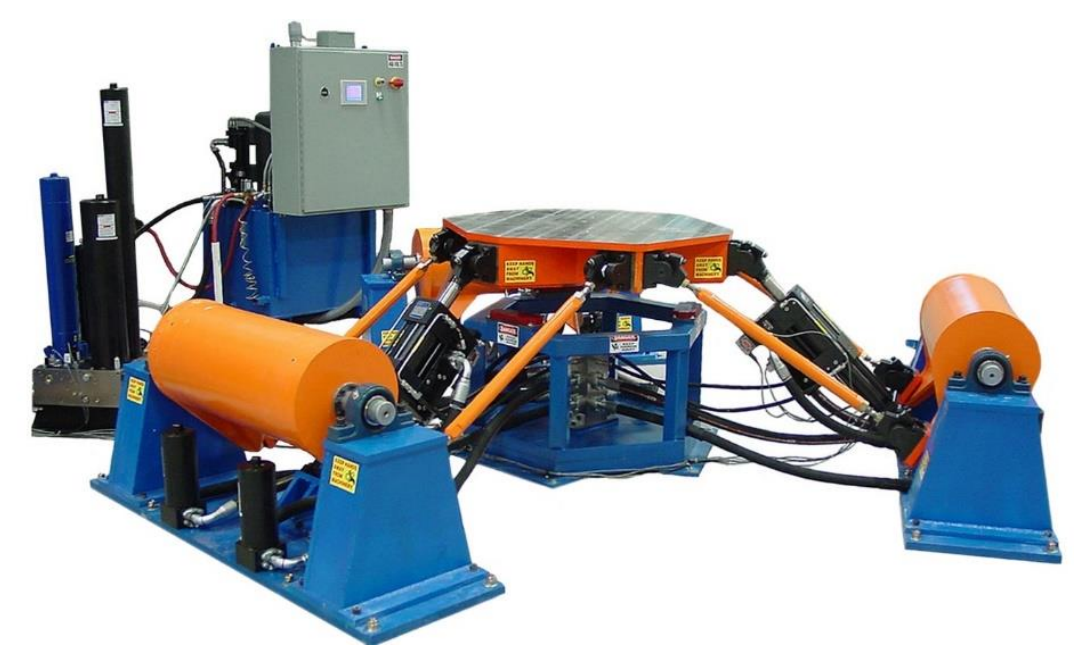

To simulate the DBEs condition (normally LOCA and HELB), it is necessary to expose the equipment to an ionising radiation for the LOCA accident (with enough margin) and after that the equipment shall be exposed in an autoclave to the temperature-time history expected in the accident considering also the high pressure of the accident. The total testing period is 48 hours maximum [[12]]. Albeit the MSLB accident does not require the application of radiation, the temperature and pressure conditions are higher than the ones for the LOCA. Laboratories around the world design and construct the chamber necessary to perform the test, e.g. at Kinetrics US, at NTS Huntville and Fauske \& Associates. One example of LOCA chamber is presented in Fig. 4. This LOCA chamber test is located in India at Research \& Development TAPS (Tarapur Atomic Power Station) 3 and 4.

Currently these types of tests are not performed in Brazil. With such qualification test expertise available in the country, Brazilian electrical equipment industry could submit their manufactured products to such qualifications and market them in Brazilian and international markets.

In addition, this qualification would make these equipment, components and systems available to the several nuclear reactor projects currently being undertaken in the country. The infrastructure and trained work force could also conduct qualification of equipment and systems of other critical industries such as airspace, naval oil and gas and transportation

Figure 4: LOCA Chamber in India at R\&D TAPS 3 and 4 [[12]]. 


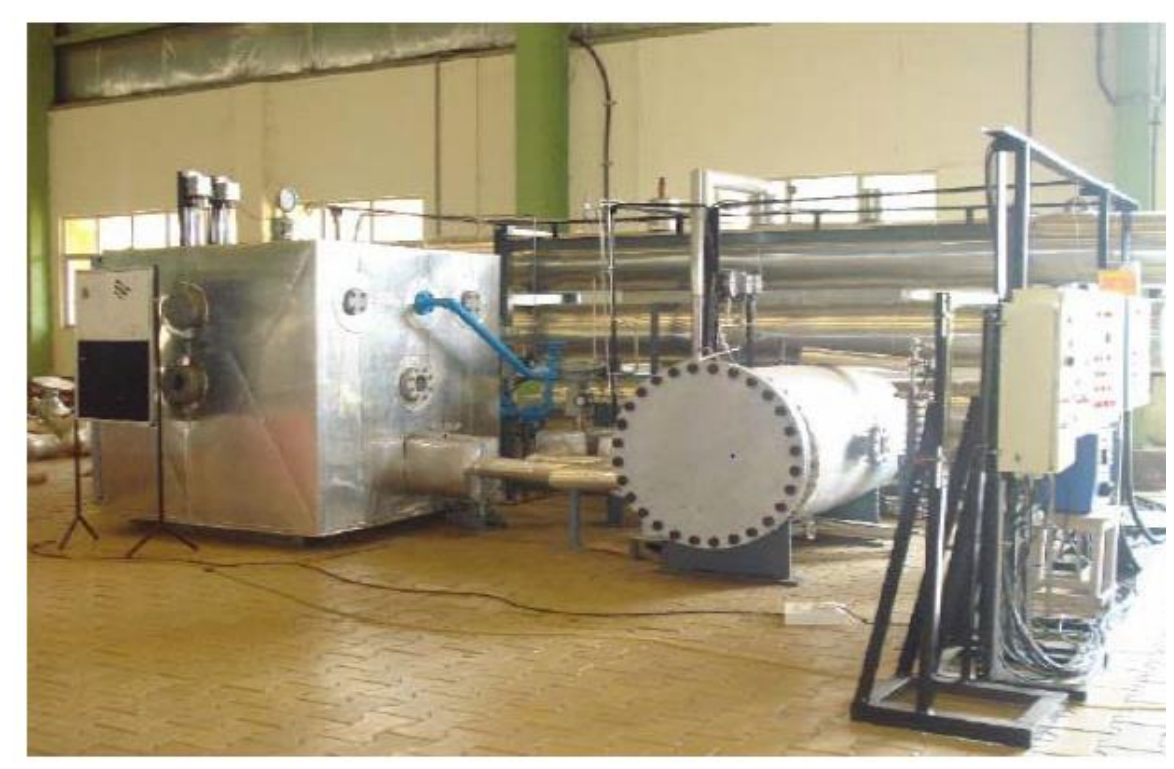

\section{CONCLUSION}

The qualification of electrical equipment to be installed is a complex activity that requires the improvement of laboratory infrastructure and specialized work force. in companies or laboratories. The article summarizes the evolution of the standards IEC 60780 and IEEE 323 until their harmonization with the standard IEC/IEEE 60780-323, it also details the qualification process established by IEC/IEEE 60780-323 focusing on the type-testing method and it finished by presenting the main tools required to perform this method of qualification.

Having this capability in the country, in research institutes or universities, Brazilian companies of electric and electronic equipment could have a means to conduct the IEC/IEEE 60780-323 qualification processes to their products and compete in the Brazilian and international markets. The market is not restricted to the nuclear sector. Other industries such as oil \& gas, transportation, airspace and naval industries demand such systems and equipment with such qualifications. For future work we intend to contact Brazilian companies, research institutes and universities to study the feasibility to install such infrastructure in the country. 


\section{ACKNOWLEDGMENT}

The last author thanks CAPES for its support for the Programa de Pós-graduação em Energia of Universidade Federal do ABC.

\section{REFERENCES}

[1] International Atomic Energy Agency, Convention on Nuclear Safety, International Atomic Energy Agency, Vienna, Austria (1994).

[2] International Atomic Energy Agency, Safety Report Series No. 3, International Atomic Energy Agency, Vienna, Austria (1998).

[3] International Atomic Energy Agency, Basic Safety Principles for Nuclear Power Plants 75INSAG-3 Rev. 1 INSAG-12, International Atomic Energy Agency, Vienna, Austria (1999).

[4] International Atomic Energy Agency, General Design Safety Principles for Nuclear Power Plants: A Safety Guide, International Atomic Energy Agency, Vienna, Austria (1986).

[5] International Electrotechnical Commission and Institution of Electric and Electronic Engineering, IEC/IEEE 60780-323: Nuclear Facilities - Electrical Equipment Important to Safety - Qualification, International Electrotechnical Commission, Geneva, Switzerland (2016).

[6] Association Française pour les Règles de Conception et de Construction des Materiels des Chaudières Électronucleaires (AFCEN), RCC-E: Design and Construction Rules for Electrical Equipment of PWR Nuclear Islands, AFCEN, Courbevoie, France (2016).

[7] General Administration of Quality Supervision, Inspection and Quarantine of People's Republic of China, GB/T 36044-2018: Qualification Procedure of Electrical Equipment Important to Safety for Nuclear Power Plant, China National Standardization Administration, Shenzen, China (2018).

[8] International Electrotechnical Commission, IEC 61513: Nuclear Power Plants Instrumentation and Control Important to Safety - General Requirements for Systems, International Electrotechnical Commission, Geneva, Switzerland (2011).

[9] Institution of Electric and Electronic Engineering, IEEE 603-2018: IEEE Standard Criteria for Safety Systems for Nuclear Power Generating Stations, Institution of Electric and Electronic Engineering, Piscataway, United States of America (2018). 
[10] G. Johnson, Comparison of IEC and IEEE Standards for Computer-Based Control Systems Important to Safety, U.S. Department of Energy, Oak Ridge, United States of America (2001).

[11] K. Spang, G. Stahl. Qualification of Electrical Components in Nuclear Power Plants, Swedish Nuclear Power Inspectorate, Stockholm, Sweden (2002).

[12] P. Kumar, "Environmental Qualification (EQ) of Safety Equipment for Indian Nuclear Power Plants (NPPs)", Workshop on Reliability and Life Assessment of Electronic Systems Methods \& Techniques, Mumbai, India (2012).

[13] Associação Brasileira de Energia Nuclear, "Programa Nuclear da Marinha", Brasil Nuclear, 49, pp. 6-7 (2018).

[14] Empresa de Pesquisa Energética, Plano Nacional de Energia 2030: Geração Termonuclear, Ministério de Minas e Energia, Brasília, Brazil (2007).

[15] “Armário de ensaio de vibrações, tipo ShakeEvent", https://www.weiss-technik.com/pt/areade-produto/armario-de-ensaio-de-vibracoes-tipo-shakeevent/.

[16] "Exciter 3D Three Degrees of Freedom Vibration Test System", https://www.linkeng.com/en/products/exciter-3d-three-degrees-freedom-vibration-testsystem. 